\title{
Functional biodiversity in the agricultural landscape: relationships between weeds and arthropod fauna
}

\author{
P BÀRBERI*, G BURGIO†, G DINELLI†, A C MOONEN*, S OTTOł, C VAZZANA \\ \& G ZANIN \\ *Land Lab, Scuola Superiore Sant'Anna, Pisa, Italy, †Dipartimento di Scienze e Tecnologie Agroambientali, Alma Mater Studiorum Università \\ di Bologna, Bologna, Italy, \$Istituto di Biologia Agroambientale e Forestale, CNR, Legnaro PD, Italy, §Dipartimento di Scienze Agronomiche e \\ Gestione del Territorio Agroforestale, Università di Firenze, Firenze, Italy and $\uparrow$ Dipartimento di Agronomia Ambientale e Produzioni Vegetali, \\ Università di Padova, Legnaro PD, Italy
}

Received 25 July 2009

Revised version accepted 5 May 2010

\section{Summary}

We reviewed studies aimed at understanding functional relationships between weeds and arthropods in agroecosystems as influenced by biodiversity at different scales, with the main goal of highlighting gaps in knowledge, research methods and approaches. We first addressed: (i) the regulation of arthropod communities by weed diversity at genetic, species and habitat levels, (ii) the regulation of weed communities by arthropods through seed predation and dispersal and (iii) belowground weed-insect interactions. We then focussed on methodologies to study weed-arthropod interactions in agricultural landscapes and discuss techniques potentially available for data analysis and the importance of joint weed-arthropod trend detection. Lastly, we discuss the implications of research findings for biodiversity conservation policies (agri-environmental schemes) and suggest some priorities for future work. Results showed that to date research has largely ignored weed-arthropod interactions in agricultural landscapes. No information is available on the role of weed genetic diversity as driver of weed-arthropod interactions, whereas studies on effects of species and habitat diversity often lack a functional perspective and/or a spatial component. Also, information on how management of the wider agricultural biotope might express positive weedarthropod functional interactions is scarce. Another area worth being explored is the relationship between weed-leaf/root herbivores and beneficial arthropods. Tools for spatial data analysis might be useful for elucidating weed-arthropod interactions in agricultural landscapes, but some methodological aspects, e.g. the definition of the most appropriate experimental design and sampling scale/frequency, must be refined. New studies on weed-arthropod interactions should encompass an explicit spatial component; this knowledge is particularly important for improving IPM/IWM systems and designing more targeted agri-environmental schemes.

Keywords: agri-environmental schemes, ecological services, entomology, food web, insects, multifunctional agriculture, trophic interactions, weed management.

Bàrberi P, Burgio G, Dinelli G, Moonen AC, Otto S, Vazzana C \& Zanin G (2010). Functional biodiversity in the agricultural landscape: relationships between weeds and arthropod fauna. Weed Research 50, 388-401.

\section{Introduction}

Agriculture and landscape: the need for interdisciplinarity and definition of scale

Agricultural use covers c. $40 \%$ of the European land surface, with values up to $70 \%$ in some areas (Hails,
2002). Nowadays, various stakeholders request nonfood services from agricultural areas (e.g. hunting, tourism, leisure, production of renewable energy, biodiversity conservation) and, in general, society expects the agricultural landscape to be aesthetically pleasant and environmentally healthy (Brandt et al., 2000). 
The non-food services required by society are increasingly influencing farming activities, through novel agricultural and rural development policies designed at scales from local to continental. To meet all demands from society, two main strategies can be identified: separation between agricultural production and other services or integration of all services provided by the rural landscape. The first option results on the one hand in highly specialised productive areas with little or no place for other landscape functions and on the other hand in nature conservation areas, possibly hosting small-scale low input farming, mainly aimed to maintain rural landscape values and where production is no longer the main goal of agricultural activities. In contrast, the second option requires integrative policies and should result in multifunctional agriculture, where farming produces food, feed, timber and non-food outputs and services for society (Idda et al., 2005).

In the latter context, interdisciplinary agroecological research is necessary for optimum planning and management of multifunctional rural areas. This includes making better use of all natural resources to develop new and sustainable agricultural practices, such as field boundary management to attract beneficial insects ('conservation biological control') or calculation of weed/pest infestation risk based on land use intensity and configuration of the surrounding landscape. In multifunctional agriculture, farm management cannot be detached from the surrounding landscape and this calls for new methodological approaches linking farming practices directly to land use patterns and agrienvironmental processes and to take into account interactions that become visible only beyond the farm gate. In this context, landscape does not necessarily refer to a large-scale study approach. Rather, the 'landscape scale' is that at which the effects of the interactions among farming practices, land use and agro-environmental processes on a given phenomenon become visible (Blaschke, 2006); this may vary from a field to a region. Strictly speaking, the 'landscape scale' is a general concept which does not give any numeric information about the size of the study area (Allen, 1998); it just refers to the importance of continuous information exchange and transfer through up-scaling and downscaling. This is particularly relevant to research on the relationships between agriculture and biodiversity.

\section{Functional biodiversity in agroecosystems}

When talking about management of biodiversity in agricultural landscapes, the need to go beyond field scale studies emerges immediately. Apart from soil organisms, most other living beings have a territory (here referred to strictly in ecological terms) that largely exceeds the cultivated field and they rely for at least part of their life cycle on semi-natural or natural elements surrounding the cultivated matrix, leading e.g. to different insect species-landscape interactions and meta-population patterns (Tscharntke \& Brandl, 2004). For example, individuals that forage across a large fraction of habitat patches can generate 'patchy populations'. Landscape structure can facilitate, impede or have no influence on the movements and dispersal of insects among habitat patches.

To successfully conserve or enhance biodiversity in agroecosystems, the objectives should be well defined, because management will change accordingly. Firstly, a distinction should be made between conservation/management for intrinsic, aesthetic, social, health or economic reasons or for the agroecosystem services that are provided. Secondly, it has to be decided if conservation/management is aimed at gene, species or habitat level - as defined by the Convention on Biological Diversity (CBD) (Parris, 2001) - or at the promotion of diversity at gene, species or habitat levels (Fig. 1). Diversity has been recognised to be important for the survival of all ecosystems. However, most scientific discussions and policies regarding biodiversity conservation in agricultural landscapes are lead by ecologists and nature conservationists (e.g. Henle et al., 2008) and are therefore usually focussed on increasing species richness and conserving flagship species and habitats (first two objectives in Fig. 1).

The conservation or promotion of diversity is unrelated to the identity of the components that provide it and does not take into account the importance of the interactions between various groups of organisms. Based on an extensive literature review, Moonen and Bàrberi (2008) concluded that scientific evidence for the importance of diversity has been proved only for three situations: (i) prevention of invasive species in seminatural or natural habitats and the control of dominant agricultural weeds; (ii) increased (agro)ecosystem resilience and stability following climate change or disturbance through the presence of redundant species which take over the (agro)ecosystem functions of species that have disappeared; and (iii) increased (agro)ecosystem functions in species-poor systems at a short time scale, because newly added species are more likely to be complementary in species-poor than in species-rich systems. However, since agroecosystems are generally species-poor compared with natural ecosystems, promotion of diversity, independent of the identity of the components, might have a positive effect on their health and resilience in most cases. To make the approach towards biodiversity promotion/conservation in agricultural landscapes more focussed, Moonen and Bàrberi (2008) have proposed an agroecosystem approach. This 


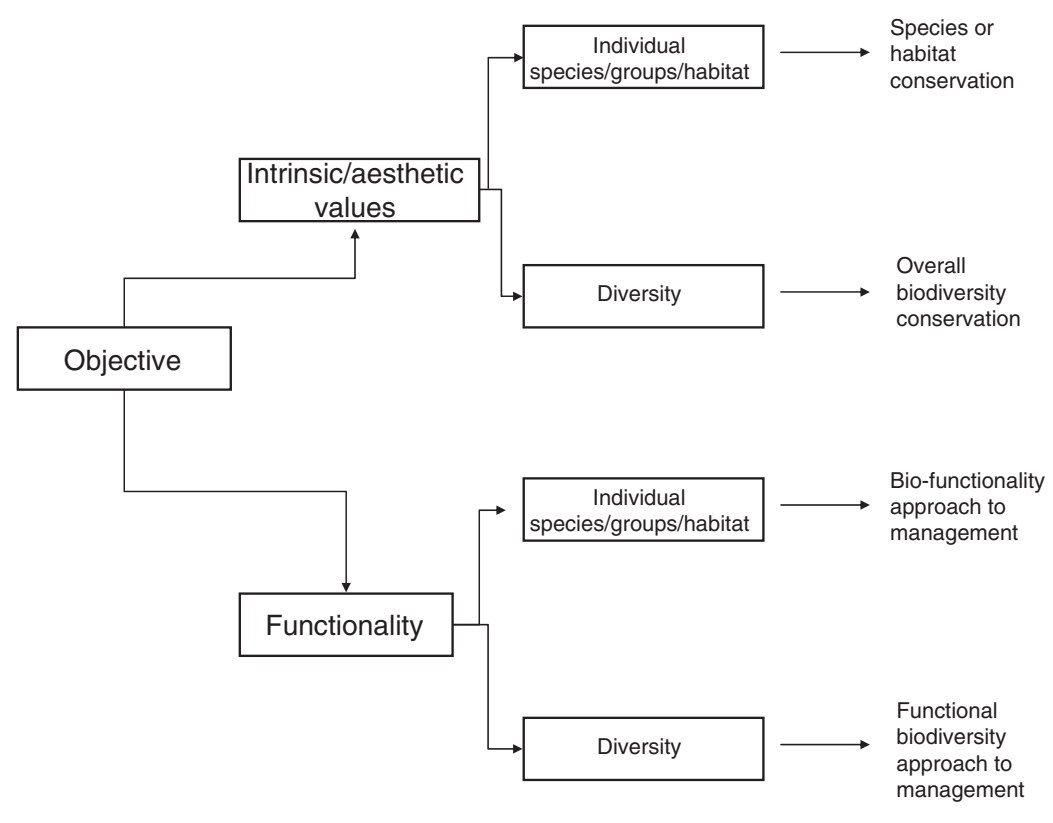

Fig. 1 Objectives of biodiversity (at sub-species, species and habitat levels) conservation and/or management and their consequences on management decisions. means that the agroecosystem should be analysed in terms of the expected/desired functions and services and of the (groups of) organisms providing or contributing to it. All those organisms can be considered to be part of the same focus group. In case the desired services are agro-environmental ones, i.e. related to agroecosystem processes, such as soil nutrient cycling or hydrological processes, microclimate or pest regulation (Altieri, 1999), the focus group can be called an 'agroecosystem functional group' (third objective in Fig. 1). It should then be proven if diversity within each group providing a given service is important or not for the fulfilment of the objective. In other words, would increased diversity within this group increase the magnitude, resilience or buffer capacity of the agroecosystem process at stake? Therefore, in agroecosystems, a more precise definition of 'functional biodiversity' would be 'that part of the total biodiversity composed of clusters of elements (at gene, species or habitat level) providing the same agroecosystem service, that is driven by within cluster diversity' (Moonen \& Bàrberi, 2008) (fourth objective in Fig. 1). If the identity of certain components is more important than the diversity among components, actions should be directed towards conservation of individual species or habitats. In this case, reference to "biodiversity' is strictly speaking not relevant, and it would be more correct to refer to 'bio-functionality'. Instead, if diversity actually contributes to increase the resilience, magnitude or buffer capacity of the desired function, management should be aimed to increase diversity of the components in the functional group. This approach is true also for the societal services (e.g. aesthetics, hunting) provided by agroecosystems and not just for production or environmental ones.
The concept of agroecosystem functional biodiversity gains importance where society aims at multifunctional agriculture. Here biodiversity is given importance not only for its nature conservation services, but especially because it provides production and environmental services, thus contributing to the development of more sustainable production methods (Altieri, 1999). It follows that biodiversity becomes an entity that has to be managed to support sustainable agriculture (Biodiversity for Agriculture) and it is not only agriculture that has to support the conservation of rare species or species appreciated by society, e.g. for aesthetic reasons (Agriculture for Biodiversity), as is the case when policies are aimed at the separation between agricultural production and nature conservation.

\section{Aim of this paper}

The aim of this paper was to review studies conducted to understand functional relationships between weeds and arthropods in agroecosystems, as influenced by biodiversity at different scales and especially to highlight gaps in knowledge, research methods and approaches which could be the subject of future research. After providing an overview of relevant weed-arthropod interactions in agroecosystems, we addressed the following issues: (i) the regulation of arthropod communities by weed diversity at the genetic, species and habitat levels; (ii) the regulation of weed communities by arthropods through seed predation and dispersal; (iii) below-ground weed-insect interactions.

Then, we tackled methodological issues to study weed-arthropod interactions in the agricultural landscape, especially focussing on techniques for data 
analysis and on the importance of joint weed-arthropod trend detection.

Lastly, we discussed the relevance and implications of research findings for biodiversity conservation policies, especially agri-environmental schemes in EU member states and we suggested some priorities for future research and policies.

In the context of this paper, we used the term 'weed' to identify any plant species not purposely introduced in the agroecosystem.

\section{Functional relationships between weeds and arthropods at different scales}

\section{Synopsis of weed-arthropod interactions}

Green plants constitute the base of the food chain as primary producers. They are food for herbivores and provide shelter, overwintering sites and reproduction (e.g. oviposition) opportunities for many animal species. This implies that vegetation hosts the prey of secondary consumers (carnivores). Therefore, structure, composition and management of the vegetation in and around fields can be considered as the drivers of biodiversity in agricultural areas (Southwood \& Way, 1970).

Most rural areas are dominated by cultivated fields, whose vegetation cover is an important determinant of all the other species that rely on it. It follows that weed vegetation in these areas should be evaluated not only for the direct damage it causes to crops through interference (mainly competition), but also for its support of other species and of the agroecosystem processes regulated by the weeds themselves and by the organisms supported by them (Altieri, 1999).

This new role attributed to weeds should be included in future research questions formulated by weed scientists (Fernandez-Quintanilla et al., 2008). For example, weed management could support what is generally called 'biodiversity conservation'. On one hand, this means the conservation of rare weed species, following the more classical approach of ecologists and conservationists (first objective in Fig. 1) (Makowski et al., 2007). On the other hand, this means that weed scientists should contribute more actively to the production of knowledge and know-how on the management of weeds to support agroecosystem functional biodiversity for the improvement of the sustainability of agricultural practices (third and fourth objectives in Fig. 1).

Many review papers explored multitrophic interactions between plants and arthropods, including weeds (e.g. Norris \& Kogan, 2000, 2005). Weeds are crucial in integrated pest management (IPM) strategies, because they provide food, shelter, alternative preys and hosts for beneficial arthropods, leading to agroecological services (Risch, 1987; van Emden, 1990). Many authors have reviewed the importance of vegetation diversity for enhancing populations of beneficial arthropods in cropland (e.g. Delucchi, 1997; Landis et al., 2000). These studies were mainly focussed on conservation biological control (CBC) (Barbosa, 1998) and are consistent with the 'enemies hypothesis', which predicts that natural enemies will be augmented in diversified agroecosystems and thereby control herbivores more effectively (Risch, 1987). CBC involves environmental manipulation to enhance the fecundity and longevity of natural enemies, to modify their behaviour and provide shelter from adverse environmental conditions. These strategies include the maintenance of ecological compensation areas (also called 'ecological infrastructures') that enhance functional biodiversity for pest suppression. In fact, the spatial scale of CBC studies is often limited to the field and its margins, whereas landscape patterns are largely ignored, with the exception of the work of Gardiner et al. (2009).

Other studies were mainly focussed on agricultural ecology and insect outbreaks also including the disadvantages of weeds (Risch, 1987). Indeed, weeds can be a source of arthropod pests for adjacent crops. In particular, non-crop habitats can harbour alternative food source for non-specialised (polyphagous) insect pests (Risch, 1987; Hillocks, 1998). Specific examples of weeds serving as alternative hosts for pest arthropods are reported by Norris and Kogan (2005) and in these cases selective management is advocated. In an agroecological context, it is important to study all potential interactions between weeds and insects, including detrimental effects. However, uncultivated habitats adjacent to crops can also become 'trap crops' (Delucchi, 1997), so that the maintenance of a small area of weeds highly attractive to the insect pest near a valuable crop can prevent its outbreak in the cultivated field (Risch, 1987). Some examples of this technique are cited in Norris and Kogan (2005), but selective management of ecological infrastructures has so far largely been ignored. Besides harbouring insect pests, some weeds can also be an alternative host of disease agents vectored by insects. Classical examples of this type of interaction include pathogens, phytoplasmas and viruses transmitted by leafhoppers, plant hoppers, whiteflies, aphids and thrips (Alma et al., 2002). There is little work on selective weed management, i.e. the control only of weeds which can host crop pests or diseases.

Despite the numerous examples of studies demonstrating the importance of weeds for the regulation of beneficial arthropods, there are only a few examples of practical applications of these findings (Delucchi, 1997; Capinera, 2005). Indeed, many papers focussed on generic enhancement of biodiversity without taking into 
account the pest control function and/or habitat planning/management to prevent pest damage. This may be due to the fact that plant species playing a key role in the management of pests and beneficial arthropods are often agricultural weeds and therefore farmers have never been very keen to adopt weed management plans other than for their control. At the same time, weed scientists themselves have mostly concentrated on weed suppression and have not invested much in maintaining the populations of functionally important weeds below damage level (Storkey, 2006). However, there are some examples that clearly demonstrated the importance of weeds to enhance the crop protection function, including the well known case of the Rubus-leafhoppers-mymarids complex (Delucchi, 1997; Landis et al., 2000).

\section{Weeds regulating arthropod communities: plant genetic diversity}

To date, relatively few experimental studies have focussed on the role of intra-specific (i.e. genetic) plant diversity as a driver of weed-arthropod interactions. Similarly, empirical data describing the relationship between intra-specific diversity and ecosystem functioning are scarce.

Foliage-based arthropods have been shown to respond to genetically variable host plant traits, such as plant biomass, leaf nutrients and secondary metabolites, resulting in the presence of unique suites of arthropod species on different host plant genotypes (Johnson \& Agrawal, 2005). Consequently, as genotypic diversity in a host plant patch increases, so does the number of arthropod species (Crutsinger et al., 2008).

A recent study showed that genotypic variation in the host plant Solidago altissima L. had strong positive effects on the diversity and composition of foliage-based arthropods (especially on herbivores and predators), but only weak effects on all trophic levels of litter-based microarthropods (Crutsinger et al., 2008). This study suggests that incorporating communities associated with living foliage and senesced litter in studies of community genetics would lead to very different conclusions on the importance of intra-specific plant diversity to when foliage-based community alone is considered. Plant genetic variation is responsible for differential ecological effects for above- and below-ground microbial communities, as recently reviewed by Schweitzer et al. (2008).

Bangert et al. (2005) defined a general rule to predict how genetic variation in a dominant plant species affects the structure of an arthropod community. The genetic similarity rule states that, on average, arthropod communities become more similar as the plants they utilise are genetically more similar (Whitham et al., 2006), according to a negative linear correlation between the
Bray-Curtis index (whose high values indicate similar arthropod communities) and the Euclidean distance (whose low values indicate closely-related plants).

The heritable genetic variation within individual species, especially dominant and keystone species, has relevant community and ecosystem consequences, which represent the extended phenotypes, i.e. the effects of genes at levels higher than the population (Whitham et al., 2003). The environmental influences on the phenotype of one species due to the expression of genes in another species are defined as interspecific indirect genetic effects (IIGEs) (Shuster et al., 2006), which have been demonstrated, for example, to modulate interactions between Populus angustifolia $\mathrm{L}$. and the leaf-galling aphid Pemphigus betae Doane (Bailey et al., 2006).

The emerging fields of community and ecosystem genetics have defined a new concept, i.e. the minimum viable interacting population (MVIP), which represents the size of a population necessary to maintain the genetic diversity at levels required by dependent and interacting species (Whitham et al., 2003). The MVIP concept can also explain the failures of many human interventions aimed at restoring ecosystem biodiversity and functioning, both in the wild and in agroecosystems. In fact, any interventions on ecosystems and habitats exclusively based on restoring inter-specific diversity, without taking into account the related intra-specific diversity, might be inefficient and inadequate. The number of studies that have examined how plant genetic factors affect arthropod community composition is still limited (Whitham et al., 2006). In particular, to our knowledge, no literature is available on the effect of weed genetic diversity on farmland arthropod populations and communities. It would be interesting to apply the above mentioned approaches to functional biodiversity studies in agroecosystems, to fill in the knowledge gaps on the interactions between weed genetic diversity and arthropods in such systems.

\section{Weeds regulating arthropod communities: plant species diversity}

Plants other than crops can influence the diversity and abundance of herbivores and associated natural enemies in agroecosystems either directly, through provision of food, nectar, pollen, shelter or reproduction sites or indirectly, through modification of the environment. An example of the latter is the enhancement of biological pest control exerted by aphidophagous Syrphidae through the use of windbreaks, which prevent wind from inhibiting the activity of adult syrphids (Bugg, 1993).

Field history and crop management are important drivers of species composition and functional structure 
of insect communities, due to their influence on canopy structure, food quality and abundance and composition of essential oils in resulting crop-weed associations (de la Fuente et al., 2006). Changes in soil characteristics can start bottom-up processes that alter the crop-weed community structure and weed species characteristics, which, in turn, affect organisms depending on them (Dicke, 1999).

Extensive reviews of trophic and non-trophic interactions occurring between insects and weeds in agroecosystems can be found in Norris and Kogan (2000, 2005), but many of the cited studies do not consider the effect of weed community level and/or spatial factors in driving these interactions. As such, despite the well known role of weed patches on insect populations, clear cut evidence of the role of weed spatial pattern on the expression of the biological pest control function is lacking.

\section{Weeds regulating arthropod communities: habitat diversity}

The scale at which the structural complexity of the landscape is measured has been shown to affect both plant-herbivore and herbivore-parasitoid interactions. To demonstrate this, Thies et al. (2003) determined the percentage of non-cropped land in concentric areas of $0.5,1,2,3,4,5$ and $6 \mathrm{~km}$ diameter around the sampling site in 15 different agricultural landscapes. Damage on oilseed rape (Brassica napus L.) by the pollen beetle (Meligethes aeneus F.) and parasitoid attack to the pollen beetle were measured and related to the percentage of non-cropped area at the different scales. Multiple regression analyses showed that the percentage of destroyed oilseed rape buds decreased and parasitism rate increased as the percentage of non-cropped area increased. These correlations were stronger in an area of $1-1.5 \mathrm{~km}$ diameter around the sampling site.

Similar findings were found by Tscharntke and Brandl (2004), who noted that the higher the trophic level (e.g. plant-insect-bird), the larger was the spatial domain in which interactions occurred and suggested a possible correlation of scale with body size and resource specialisation. In fact, large generalist predators that depend on several prey species may inhabit different (micro)habitats and they may explore a larger area than small parasitoids that depend on one or a few host species.

At the field scale, to date the most explored one, several studies (e.g. Paoletti \& Lorenzoni, 1989; Burgio et al., 2007) have documented the positive effect of weeds bordering cropped fields on the dynamics of colonising insect pests, especially when weed vegetation was botanically related to the crop. In contrast, certain weeds (mostly from the Apiaceae, Asteraceae and Fabaceae families) play an important ecological role by nurturing a complex of beneficial arthropods (Norris \& Kogan, 2005). It follows that field boundaries, if properly managed, can provide alternate food sources and habitats to natural enemies that move into neighbouring crops (Altieri, 1999). However, Girma et al. (2000) demonstrated that the effect of hedgerows on pest infestations of crops and their role as refugia for predators cannot be generalised and depends on the specific arthropods. Moonen et al. (2006) showed that the structural heterogeneity of the field margin complex (hereafter referred to as any structure comprised between the edges of two adjacent cropped fields) was inversely correlated with the abundance of agriculturally important weeds in the complex, but also with the abundance of aphid predators (mainly Coccinellidae and Syrphidae), because the latter depend on the presence of some of these weeds during part of their life cycle. Therefore, it is likely that the same level of habitat diversity turns into higher or lower expression of agroecological functions (e.g. prevention of weed invasion from the margins or biological pest control), depending on the given ecological features of weed and insect components.

\section{Arthropods regulating weed communities: seed predation and dispersal}

Plants are immobile and have therefore developed a range of strategies to avoid, tolerate or defend against insect herbivores. Seed predation is a special type of herbivory and results in significant and often complex effects on weed population dynamics. It is therefore not surprising that the removal of herbivores has often been found to increase plant population size or fitness and to alter the pattern of selection or genetic variation in chemical and morphological traits that have been shown to reduce herbivore damage on plants in the field (McEvoy, 2002).

The reduction in plant biomass by herbivory can be equal in magnitude to that resulting from competition (Gurevitch et al., 1992), the effect of invertebrates being significantly stronger than that of vertebrates. The probability of a herbivore locating a host plant population in the landscape can be related to population size and to where it is located in relation to other plant populations. Environmental conditions are also an indirect source of variation in intensity of insect-plant interactions, due to their impact on phenotypic trait levels of host plant populations.

It is difficult to detect the actual effect of seed predation on weed population dynamics. Seed predation can occur while seeds are still attached to the mother 
plant (pre-dispersal) or post-dispersal. Pre-dispersal seed predators are usually invertebrates (mainly insects: Coleoptera, Diptera, Hymenoptera and Lepidoptera) with a narrow host range or specialised feeding habitat. When clearly identified, these insects can be used as direct biological weed control agents.

In contrast, there is a wide variety of post-dispersal predators and seed consumers, including generalist vertebrates (birds, rodents) and invertebrates (Coleoptera, Hymenoptera, earthworms, molluscs, etc.). Postdispersal predation can occur both on the soil surface and below it. Surface seed predation depends on the duration of seed exposure to predators, which in turn depends on the time lag between seed shedding and incorporation in soil. Tillage system, soil organic matter content, presence of surface residues and seed traits (e.g. size, presence of awns, specific weight) are important factors influencing surface seed predation.

Westerman et al. (2005) showed that predation by opportunist invertebrates can substantially reduce the surface weed seed stock. Specific examples of weed seed predation by carabid beetles have been reviewed by Tooley and Brust (2002). Shearin et al. (2008) studied the effects of different cover crops on the predation activity of the carabid Harpalus rufipes Degeer. However, these studies have rarely included data on the actual decrease of weed pressure due to seed predation.

Any interventions altering trophic interactions among different organisms (e.g. insecticide applications) can substantially diminish weed seed predation rate. On the other hand, it should be noted that some plants have developed defences against seed predators. For example, producing large seeds at irregular time intervals is an indirect defence method against seed predation, because it reduces the chances that seeds will be consumed all at once by predators. There are just a few studies (e.g. DeSousa et al., 2003) that have highlighted the effect of pre-dispersal seed predation on weed populations and so, actual application in agroecosystems is scarce.

In general, conservation tillage practices (including the use of cover crops) maintain or increase the activity of invertebrate predators (Carmona \& Landis, 1999). Landis and Marino (1999) asserted that weed seed predation should be higher in agricultural landscapes characterised by a higher rate of non-cropped areas, because these habitats can host a more diversified community of seed-feeding animals. Weed seed predation is then likely influenced by soil disturbance regime, whose effect seems more relevant in less intensive agricultural areas (Westerman et al., 2003). Although this hypothesis has not yet been completely validated, it is intriguing because it suggests that weed communities may be manipulated by interventions aimed not only at field level but also at the level of the wider agricultural biotope.

While seed predation by insects can be an important factor regulating weed community densities, seed dispersal by insects can regulate the spatial configuration of weed populations, either by concentrating seeds that were scattered from the mother plant or by dispersing them. Many insects (ants, beetles, bugs, wasps and some moths) feed on weed seeds, thereby possibly contributing to their dispersal. This is particularly common in the case of ants: due to their seed preference, ants may selectively remove dominant small seeds and hence increase weed community evenness (Risch \& Carroll, 1986). Seed dispersers are beneficial to the recruitment of the next seedling generation and a key factor in determining the spatial and temporal distribution of weed populations. Seeds also move vertically in soil due to insect burrowing activities (Chambers \& MacMahon, 1994). This behaviour may increase the availability of 'safe sites' and consequently the germination and establishment of weed seedlings. Surprisingly, studies taking into account the impact of landscape configuration and land use patterns on seed dispersal by insects are lacking whereas plant insect pollination in agricultural landscapes has been shown to increase in patches connected by linear landscape elements (van Geert et al., 2010). Clearly, functional interactions across trophic levels mediated by weed seeds still have to be fully elucidated (Franke et al., 2009).

\section{Below-ground weed-insect interactions}

Studies exploring community-level processes have been based primarily on bi- or tri-trophic interactions in above-ground systems, usually involving associations among plants, herbivores and their natural enemies. Recently, it has become apparent that above-ground trophic interactions can be strongly influenced by interactions occurring between the host plant and soildwelling organisms (Tindall \& Stout, 2001). Also, interactions between above- and below-ground herbivores can be mediated by qualitative changes in the shared host plant. Bezemer and van Dam (2005) showed that root herbivory can result in enhanced concentrations of secondary metabolites in the foliage, although the reverse has rarely been reported. Moreover, herbivory can induce a stress response in the host plant, which can lead to reallocation of compounds, such as carbohydrates and soluble nitrogen, between root and shoot tissues.

Herbivore damage on plant shoots can have significant negative effects on the development of belowground herbivores and their natural enemies. Soler et al. (2007) highlighted the importance of integrating the 
below-ground domain with the above-ground one, to better understand the manifold factors shaping the evolution, assembly and functioning of communities and ecosystems. They also showed that root herbivores can influence above-ground host-parasitoid interactions via changes in the attractiveness of surrounding conspecific plants.

Feeding by herbivores often triggers the emission of specific blends of plant volatiles that attract herbivore predators and parasitoids, which can potentially reduce herbivore damage and thus increase plant fitness. These studies have also shown that the development and behaviour of herbivores and their natural enemies can be influenced by root herbivores that share the same host plant. It also seems that above-ground, leaf-eating insects prefer plants that have not yet been attacked by subterranean, root-eating insects (Soler et al., 2007). This behaviour may be an adaptive response that, for example, enables the parasitoid mother to avoid high levels of phytotoxins induced in plant foliage by root herbivores, which would otherwise negatively affect her progeny. This is a fascinating area of applied ecology that deserves further investigation. There is basically no information available on weed above-ground insect below-ground interactions, yet elucidation of them would provide interesting insights on the causes of spatial and temporal dynamics of weed and arthropod populations.

\section{Methodologies to study weed-arthropod interactions in the landscape}

Field studies of weed-arthropod interactions must inevitably involve a spatial component. The first difficulty that arises is the definition of the spatial scale at which interactions should be investigated. At first, it would seem that the best choice is the spatial scale corresponding to the activity range of the most mobile species of those included in the trophic interaction studied. However, as previously pointed out, Thies et al. (2003) and Tscharntke and Brandl (2004) showed that the highest expression of functional relationships involving insects can be found at intermediate scales.

Introducing a spatial component in these studies is challenging for the choice of the experimental design, which requires large plots, if not entire fields. This is especially true when studying highly mobile natural enemies, such as parasitoids or coccinellids (Perry, 1997). Practical difficulties include situations in which effects such as 'relative isolation' need to be measured, e.g. in terms of distance of a plot from a hedgerow or the nearest source of re-colonising and overwintering insects (Perry, 1997). Randomisation for such factors requires care and in some situations is impossible. Ensuring adequate replication in trials which compare different degrees of isolation of patches entails inclusion of a large study area and some specific experimental designs have been proposed to overcome these problems (Perry, 1997). In any case, planning experiments on weed-insect interactions which include a spatial component brings methodological problems that often cannot be addressed by classical experimental designs.

Weeds are obviously less mobile than many arthropods. Nevertheless, substantial differences in their activity range can be observed, due to diverging seed dispersal-related traits. Compared to anemochorous species, barochorous ones (i.e. those whose seeds are mainly dispersed by gravity) have a much smaller scale of distribution. Wilson and Aebisher (1995) studied the distribution of dicotyledonous arable weeds in relation to their distance from the field edge. Results showed that for most species density decreased significantly as distance from crop edge increased from 0 to $128 \mathrm{~m}$. These findings are probably applicable to many grass weeds too and are consistent with those of Marshall (1989), who mapped weed species distribution along a transect of some metres from a hedgerow into a cereal field, highlighting the importance of addressing the 'small' (metre or tens of metres) scale when studying crop edge effects on arable weeds.

Crop management can affect vegetation composition in the field margin complex, but the reverse is also true. This mutual interference likely results in (or is affected by) an environmental gradient (e.g. nutrients or pesticide concentration, topsoil texture and moisture), from the field margin complex to the field centre and vice-versa. Many methods and techniques are available to assess the link between variables varying in space.

\section{Data analysis}

Data collected to study weed-insect interactions can be analysed by classical techniques, e.g. general linear models (GLMs) or by more advanced ones, like geostatistics and neural networks. A detailed discussion of these techniques is beyond the scope of this paper: here we only present a synopsis of the subject and focus on the approaches that might offer the greatest potential.

In general, methods can be divided in 'hypothesis testing' (when experimental units are arranged in classical experimental designs) and 'structure detecting' (when experimental units are selected but randomisation is incomplete). In hypothesis testing methods, randomisation is the only way to control external sources of variation. This is a widely used approach but often criticised; its main alternative is Bayesian inference, in which evidence or observations are used to update or newly infer the probability that a hypothesis might be 
true. The Bayesian statistical approach has rarely been used in agroecology, but some examples are available (Gliessman, 1998). Structure detecting methods include e.g. geostatistics, which are a set of techniques specifically designed to describe the spatial variability of data and advanced methods like neural networks.

General linear models (GLMs) include different statistical models like ANOVA, ANCOVA, MANOVA, MANCOVA, ordinary linear regression, $t$-test and $F$-test. An extension of multivariate approaches like MANOVA or MANCOVA are multivariate analysis techniques (e.g. classification methods like cluster analysis or ordination methods like principal component analysis) which allow identification of qualitative relationships between weed or arthropods species abundance and soil/habitat properties, provided that the number of variables does not exceed that of observations (Kenkel et al., 2002). The results can typically be summarised with informative biplots or triplots. The multivariate approach is widely used in applied ecology to correlate insect diversity with sites, plant components, weed species or other ecological variables. Several examples of weedinsect associations explored by multivariate analysis can be found in Burgio (2007).

Sometimes, sampling schemes based on 'random effects ANOVA' can provide a more reliable characterisation of spatial structure than that provided by spatially-dependent geostatistical models, whose basic assumption of stationarity is often violated in patchy landscapes (Davidson \& Csillag, 2003). However, ANOVA linear models require many strong assumptions, including true randomisation and proper replication of treatments, which can rarely be met in landscape-based weed-arthropod interaction studies.

Among specific structure detecting methods, assessment of the spatial pattern related for example, to the effect of a field margin complex or other gradient can be done using geostatistical gridding methods, that is, kriging interpolation. Sampling needed to obtain a reliable grid can be very time consuming and must be congruous with the spatial scale of the studied phenomenon, but results can be very explanatory (Zanin et al., 1998). One of the main advantages of this method is that it can allow the identification and visualisation of an environmental gradient. Also, this approach enables the identification and interpretation of border effects and the visualisation of weed-insect population dynamics and their relationship with crops.

Besides their apparent simplicity, geostatistical methods include many auto-correlation models (semivariograms, correlograms, covariance functions) and interpolation methods (stochastic and deterministic), which must be selected cautiously. For example, stochastic kriging methods include a number of geostatis- tical interpolations, like ordinary kriging, universal kriging and co-kriging. On the other hand, deterministic interpolation methods create surfaces from measured points, based on either the extent of similarity (e.g. inverse distance weighted) or the degree of smoothing (e.g. radial basis functions). These techniques do not use model of random spatial processes typical of stochastic methods (e.g. semivariogram).

Among geostatistical tools, a binary data estimator is available: indicator kriging. This is a powerful tool which calculates probability functions of a binary variable, leading to the visual representation of the spread of a pest or weed (probability map), very useful for site-specific pest/weed management (Park \& Tollefson, 2006).

Space-time geostatistical approaches have been used in both weed research (Kyriakidis \& Journel, 1999) and entomology (Perry et al., 2002). A new approach called spatial analysis by distance indices (SADIE) has been reported by Perry et al. (2002). Despite the availability of geostatistical methods and approaches, few examples to specifically analyse weed-insect interactions have been developed, though a case study was provided by Ragaglini et al. (2005), who studied field-scale interactions between weeds and Aphis fabae Scop. in conventional and low-input sugar beet.

Neural networks is a quite new and very powerful method for detecting structure and trends governed by complex mathematical functions that are too difficult to model using analytical or parametric techniques. Neural networks could be very useful as prediction methods in agroecological studies (including weed-arthropod interactions), due to their versatility. Examples of artificial neural network-based modelling in agroecology are reported in Jiménez et al. (2008).

\section{The importance of joint weed-arthropod trend detection}

Usually, variation in weed abundance can be observed in a range of few metres (Marshall, 1989) while that of arthropods can also occur in a range of hundreds of metres (Thies et al., 2003). As such, the study of joint weed-insect pattern distributions must encompass a correct sampling scheme, for example, based on the pattern with the smallest scale (i.e. a dense grid), otherwise trends would not be detected. Given that the optimal range is the greatest, this would result in an increasing sampling effort. If the abundances of weeds and predators are directly correlated and if weed abundance is higher closer to the field margin, there is an evidence of positive effect of field margin on predator abundance. But such 'simple effects' are probably rare, because of the likely interactions and substitutions 
occurring between and within trophic levels. Therefore, it can be expected that abundance pattern of arthropods and weeds vary across different scales. This subject is still poorly studied and deserves further investigation (e.g. according to the emerging concept of MVIP), because management and policy actions should consider that interventions would have a measurable effect only when applied (and measured) at the proper spatial scale.

The complexity of variables involved in the study of weed-arthropod interactions in agricultural landscapes impedes the standardisation of statistical methods, but offers the opportunity to design innovative, tailor-made techniques for experiment planning and data analysis. In any case, this will remain a challenging methodological issue.

\section{Implications for biodiversity conservation policies}

\section{Agri-environmental schemes for landscape biodiversity}

Agri-environmental schemes (AES) provide direct and conditional incentives to land users to adopt biodiversity-friendly practices worldwide (World Bank, 2006). The rise of AES popularity stems not only from increased recognition of the role played by biodiversity in ecosystem functioning, but also from increased awareness of the fragility of most ecosystems. The most extensive of these actions are the governmental AES activated across Europe and North America, providing regular payments to farmers who commit to provision of agri-environmental services, including carbon sequestration, biodiversity support and watershed protection. For example, Great Britain's Environmental Stewardship Scheme (DEFRA, 2005) conserves more than 570000 ha by paying farmers to take up environmentally-benign land use practices, whereas the U.S. Department of Agriculture's Conservation Reserve Program (CRP) pays farmers to keep erosion-prone land out of farming (Gruere et al., 2003).

In the EU, the role of farmers via AES is officially acknowledged in the Common Agricultural Policy. Institutional design of contracts differs among EU member states and regions but AES, even when tailormade to regional environmental issues, are generally not selected on the basis of commonly agreed criteria (Wilson \& Hart, 2002). Since 1992, the application of AES has been compulsory for Members States in the framework of their rural development plans (EEC, 1998). From 2003, EU member states must define AES to support farmers to preserve and implement biodiversity at different hierarchical levels, including conserva- tion of high nature value (HNV) farmland presently under threat.

The level of detail and implementation of AES in the EU varies considerably. Most of the utilised agricultural land in Austria, Finland, Germany, Luxembourg and Sweden is under AES, unlike the situation in Belgium, Greece, Italy, the Netherlands and Spain. Remarkably, the countries having the highest share of HNV farmland (e.g. Mediterranean ones) are just those with the lowest adoption rate of AES (European Environment Agency, 2004), which clearly indicates the existence of a gap between land suitability to AES and the present level of policy-driven interventions to support biodiversity in agroecosystems. Besides this, AES aimed at biodiversity are poorly monitored (Donald et al., 2002) and early schemes were often not effective (Kleijn \& Sutherland, 2003). Furthermore, there is a low level of participation in biodiversity-aimed AES in EU regions characterised by intensive farming, due to lack of competitiveness of payments against farmers income relative to conventional, high input management (Siebert et al., 2006).

Recently, European success stories of landscape management projects aimed to functional biodiversity were collected and published (de Snoo et al., 2006). This paper reported experiences from projects run in Germany, Italy, Switzerland, the Netherlands and the UK. Several indicators were used, belonging to the 'people', 'planet' and 'profit' domains. Aspects like the increase in biodiversity and beneficial arthropod populations were investigated. Three of the projects had a direct focus on the enhancement of functional biodiversity at the local scale. Indicators belonging to the 'planet' domain (i.e. reduction of pest populations, increase in beneficial arthropods, increase in biodiversity and reduction of water and soil contamination) received more attention. It appeared that enhancement of landscape management for biological conservation goals was particularly successful. Indicators belonging to the 'people' domain (i.e. acceptance of functional biodiversity by farmers and advisors, number of farmers involved, network of stakeholders, acceptance of public, influence on policy makers) received more attention than initially foreseen. Some indicators belonging to the 'profit' domain, like cost/benefit analysis of landscape management and of ecological compensation areas were less studied. This analysis can be seen as a first step towards a more thorough evaluation of landscape-based AES, which should encompass weed-arthropod interactions. Most of the European AES target the reduction of negative externalities of agricultural practices (indirect approach) and only a few target the provision of ecological benefits (direct approach). A likely explanation of this is that agriculture, under the umbrella of multifunctionality, generates many beneficial effects that 
are difficult to measure and consequently to quantify in monetary value.

Arnaud et al. (2006) provided information about priorities set forth in AES in $10 \mathrm{EU}$ partner regions. Results showed that three regions out of 10 indicated biodiversity and landscape loss as the first priority to be addressed by AES, five indicated it as second priority and one as third priority, with only one region (Flanders, Belgium) showing lack of interest in this issue. Despite this, only a minority of European AES have so far included enough (agro)ecologically-based details to expect farmers' actions to turn into concrete results in terms of biodiversity conservation. Exceptions are 'entry level stewardships' and especially 'higher level environmental stewardships' set forth in the UK by Natural England (2008a,b).

For successful targeting of AES, it would be important to consider their implementation across time and space and to base evaluation of their effectiveness on scientific criteria (to date only partly available), which take into account all the functional relationships involved. Instead, much of the efforts have so far been directed towards biodiversity conservation per se and not to the enhancement of functional biodiversity in agroecosystems (Lazzerini et al., 2007; Moonen \& Bàrberi, 2008), although some of the actions included in AES, e.g. conservation or (re)introduction of hedgerows and/or field margins, are expected to increase agroecological services besides general biodiversity. AES sometimes refer to natural field vegetation (including weeds) as an important component of biodiversity conservation, given their crucial role in the food web, but what they usually lack is reference to the importance to consider actions addressed at different scales to promote functional biodiversity in agroecosystems. This is where elucidation of weed-arthropod interactions in agricultural landscapes should find a place. These considerations should hopefully be included in future EU policies aimed at biodiversity and landscape conservation.

\section{Conclusions and future perspectives}

To date, agronomists and weed scientists have mainly carried out studies at a field or farm scale, largely ignoring trophic and non-trophic interactions occurring among agroecosystems components in agricultural landscapes. Although entomologists seem keener to take on methods typical of landscape ecology, studies encompassing also the weed component besides pests and their natural enemies are still scarce. As such, there is potential to conduct innovative interdisciplinary research on functional biodiversity-related subjects and hence increase knowledge on the drivers of weed- arthropod interactions in agroecosystems across different spatial and temporal scales. This knowledge would be of utmost importance for fine-tuning management actions and designing improved agri-environmental schemes aimed at enhancing the agroecological services related to pest and weed management.

The major factors limiting investigations on functional biodiversity in the agricultural landscape and on weed-arthropod relationships are both economic and cultural. For example, to critically address higher order genetic effects within the framework of complex and highly dynamic communities (e.g. those of agroecosystems), a relevant economic effort is required (long-term experiments, measurements on nutrient cycles, repeated sampling on insect and weeds, molecular markers, quantitative trait loci, geographical information systems, etc.). Besides this, comprehensive functional biodiversity studies require an inter-disciplinary approach combining a wide range of expertise (e.g. molecular biology, genetics, plant and crop physiology, entomology, weed science, soil chemistry and biochemistry, agronomy, ecology), whose importance is increasingly recognised in principle, but not yet in practice.

Despite this, agroecosystems have the advantage over natural ecosystems in being more easily manipulated experimentally, for example, imposing different levels of genetic variation by selecting different crops or cultivars and/or modifying the associated agricultural practices (e.g. organic versus conventional management). These are in turn expected to influence variation at gene, species and habitat level in weed and arthropod components and consequently modulate their interactions and the extent of associated agroecological services. Incorporating a spatial component in such studies might help map the likely extent of these agroecological services across the cultivated landscape.

Many research tools already developed for spatial analysis might be successfully used to elucidate weedarthropod interactions in agricultural landscapes, but some methodological aspects implied by interdisciplinary studies, for example, the definition of the most appropriate experimental design, sampling scale and sampling frequency, need to be refined.

There is basically no information available on the role of weed genetic diversity as driver of weedarthropod interactions, whereas studies on the effects of species and habitat diversity, despite being more numerous, often lack a true functional biodiversity perspective and/or an explicit spatial component. Also, very little information is available on management actions on the cultivated field and/or the field margin complex specifically targeted to increase the expression of positive weed-arthropod functional interactions. Besides this, encouragement of new and promising 
research fields, either already addressed in agroecosystems (e.g. weed seed predation) or adaptable from ecological studies carried out in other ecosystems (e.g. weed-leaf herbivore-root herbivore-natural enemy relationships) would help elucidate the extremely complex web of interactions occurring between weeds and arthropods in agricultural landscapes and hence provide a solid scientific base for the development of novel and improved IPM/IWM strategies and agri-environmental schemes.

\section{References}

Allen T (1998) The landscape 'level' is dead: persuading the family to take off the respirator. In: Ecological Scale (eds D Peterson \& V Parker), 35-54. Columbia University Press, New York, NY, USA.

Alma A, Soldi G, Tedeschi R \& Marzachi' C (2002) Ruolo di Hyalestes obsoletus Signoret (Homoptera: Cixiidae) nella trasmissione del legno nero della vite in Italia. Petria 12, 411-412.

Altieri MA (1999) The ecological role of biodiversity in agroecosystems. Agriculture, Ecosystems and Environment 74, 19-31.

Arnaud S, Bonnieux F \& Dupraz P (2006) Agri-environmental programs in the United States and European Union. In: Proceedings of ITAES Final Workshop, Venezia, Italy, 14-16 December.

Bailey JK, Wooley SC, Lindroth RL \& Whitham TG (2006) Importance of species interactions to community heritability: a genetic basis to trophic-level interactions. Ecology Letters 9, 78-85.

Bangert RK, Turek RJ, Martinsen GD, Wimp GM, Bailey JK \& Whitham TG (2005) Benefits of conservation of plant genetic diversity on arthropod diversity. Conservation Biology 19, 379-390.

Barbosa P (ed.) (1998) Conservation Biological Control. Academic Press, San Diego, CA, USA.

BEZEMER TM \& VAN DAM NM (2005) Linking aboveground and belowground interactions via induced plant defenses. Trends in Ecology and Evolution 20, 617-624.

Blaschke T (2006) The role of spatial dimensions within the framework of sustainable landscapes and natural capital. Landscape and Urban Planning 75, 198-226.

Brandt J, Tress B \& Tress G (eds) (2000) Multifunctional Landscapes: Interdisciplinary Approaches to Landscape Research and Management. Conference Material for the Conference on 'Multifunctional Landscapes', Centre for Landscape Research, Roskilde, Denmark, 18-21 October.

BuGG RL (1993) Habitat manipulation to enhance the effectiveness of aphidophagous hover flies (Diptera: Syrphidae). Sustainable Agriculture: News and Technical Reviews from the University of California Sustainable Agriculture Research and Education Program 5, 12-15.

Burgio G (2007) The Role of Ecological Compensation Areas in Conservation Biological Control. PhD thesis, Wageningen University, the Netherlands.

Burgio G, Lanzoni A, Navone P, van Achterberg K \& Masetti A (2007) Parasitic Hymenoptera fauna on
Agromyzidae (Diptera) colonising weeds in ecological compensation areas in northern Italian agroecosystems. Journal of Economical Entomology 100, 298-306.

Capinera JL (2005) Relationships between insect pests and weeds; an evolutionary perspective. Weed Science 53, 892901.

CARMONA DM \& LANDIS DA (1999) Influence of refuge habitats and cover crops on seasonal activity-density of ground beetles (Coleoptera: Carabidae) in field crops. Biological Control 28, 1145-1153.

Chambers JC \& MacMahon JA (1994) A day in the life of a seed: movements and fates of seeds and their implications for natural and managed systems. Annual Review of Ecology and Systematics 25, 263-292.

Crutsinger GM, Collins MD, Fordyce JA \& SAnders NJ (2008) Temporal dynamics in non-additive responses of arthropods to host-plant genotypic diversity. Oikos 117, 255-264.

Davidson A \& Csillag F (2003) A comparison of nested analysis of variance (ANOVA) and variograms for characterizing grassland spatial structure under a limited sampling budget. Canadian Journal of Remote Sensing 29, 43-56.

DEFRA (2005) The Environmental Stewardship Schemes. Available at: http://www.naturalengland.org.uk/ourwork/ farming/funding/es/default.aspx (last accessed: June 2009).

Delucchi V (1997) Una nuova frontiera: la gestione ambientale come prevenzione. In: Atti della Giornata sulle Strategie Bio-ecologiche di Lotta Contro gli Organismi Nocivi (eds R Prota \& RA Pantaleoni), Sassari, Italy, 11 April, 35-57.

DeSousa N, Griffiths JT \& Swanton CJ (2003) Predispersal seed predation of redroot pigweed (Amaranthus retroflexus). Weed Science 51, 60-68.

Dicke M (1999) Are herbivore-induced plant volatiles reliable indicators of herbivore identity to foraging carnivorous arthropods? Entomologia Experimentalis et Applicata 91, 131-142.

Donald PF, Pisano G, Rayment MD \& Pain DJ (2002) The Common Agricultural Policy, EU enlargement and the conservation of Europe's farmland birds. Agriculture, Ecosystems and Environment 89, 167-182.

EEC (1998) Working Document 'State of application of regulation (EEC) n²078/92. Evaluation of Agri-Environment Programmes', VI/7655/98,9.11.1998.

van Emden HF (1990) Plant diversity and natural enemy efficiency in agroecosystems. In: Critical Issues in Biological Control (eds M Mackauer, LE Ehler \& J Roland), 36-80. Intercept Ltd, Andover, UK.

European Environment Agency (2004) High Nature Value Farmland. Characteristics, Trends and Policy Challenges. Office for Official Publications of the European Communities, Luxembourg.

Fernandez-Quintanilla C, Quadranti M, Kudsk P \& BÀrberi P (2008) Which future for weed science? Weed Research 48, 297-301.

Franke AC, Lotz LAP, van der Burg WJ \& van Overbeek L (2009) The role of arable weed seeds for agroecosystem functioning. Weed Research 49, 131-141.

de la Fuente EB, Lenardis AE, Suarez SA, Gil A \& Ghersa CM (2006) Insect communities related to wheat and coriander cropping histories and essential oils in the Rolling 
Pampa, Argentina. European Journal of Agronomy 24, 385-395.

Gardiner MM, Landis DA, Grantton C et al. (2009) Landscape diversity enhances biological control of an introduced crop pest in the north-central USA. Ecological Applications 19, 143-154.

van Geert A, van Rossum F \& Triest L (2010) Do linear landscape elements in farmland act as biological corridors for pollen dispersal? Journal of Ecology 98, 178-187.

Girma H, Rao MR \& SithanAntham S (2000) Insect pests and beneficial arthropod populations under different hedgerow intercropping systems in semiarid Kenya. Agroforestry Systems 50, 279-292.

Gliessman SR (1998) Agroecology and sustainability. In: Proceedings INTECOL Symposium 8.2, July 1998, Firenze, Italy.

Gruere G, Klonsky K \& Goodhue R (2003) Do farms provide more than food? Public perspectives in California. Agricultural and Resource Economics Update 6, 9-11.

Gurevitch J, Morrow LL, Wallace A \& Walah JS (1992) A meta-analysis of competition in field experiments. American Naturalist 140, 539-572.

HaILs RS (2002) Assessing the risks associated with new agricultural practices. Nature 418, 685-688.

Henle K, Alard D, Clitherow J et al. (2008) Identifying and managing the conflicts between agriculture and biodiversity conservation in Europe - a review. Agriculture, Ecosystems and Environment 124, 60-71.

Hillocks RJ (1998) The potential benefits of weeds with reference to small holder agriculture in Africa. Integrated Pest Management Reviews 3, 155-167.

Idda L, Madau FA, Orrù E, Pulina P \& Sini MP (2005) Efficacy of European policies on rural landscape: the case study of Sardinia (Italy). In: Proceedings of the XIth Congress of the European Association of Agricultural Economists, Copenhagen, Denmark, 24-27 August.

Jiménez D, Pérez-Uribe A, Satizábal H, Barreto M, Van DAmme P \& Tomassini M (2008) A survey of artificial neural network-based modeling in Agroecology. In Soft Computing Applications in Industry (ed. B PRASAD), STUDFUZZ 226, 247-269.

Johnson MTJ \& Agrawal AA (2005) Plant genotype and environment interact to shape a diverse arthropod community on evening primrose (Oenothera biennis). Ecology 86, 874-885.

Kenkel NC, Derksen DA, Thomas AG \& Watson PR (2002) Multivariate analysis in weed science research. Weed Science 50, 281-292.

Kleijn D \& Sutherland WJ (2003) How effective are European agri-environment schemes in conserving and promoting biodiversity? Journal of Applied Ecology 40, 947-969.

Kyriakidis PC \& Journel AG (1999) Geostatistical spacetime models: a review. Mathematical Geology 31, 651-684.

LANDIS DA \& MARINO PC (1999) Landscape structure and extra-field processes: impact on management of pests and beneficials. In: Handbook of Pest Management (ed. J Ruberson), 79-104. Marcel Dekker, New York, NY, USA.

LANDis D, Wratten SD \& Gurr G (2000) Habitat manipulation to conserve natural enemies in arthropod pests in agriculture. Annual Review of Entomology 45, 173-199.
Lazzerini G, Camera A, Benedettelli S \& Vazzana C (2007) The role of field margins in agro-biodiversity management at the farm level. Italian Journal of Agronomy/ Rivista di Agronomia 2, 127-134.

Makowski D, Dore T, Gasquez J \& Munier-Jolain N (2007) Modelling land use strategies to optimise crop production and protection of ecologically important weed species. Weed Research 47, 202-211.

Marshall EJP (1989) Distribution patterns of plant associated with arable field edges. Journal of Applied Ecology 26, 247-257.

McEvoy PB(2002) Insect-plant interactions on a planet of weeds. Entomologia Experimentalis et Applicata 104, 165-179.

MoOnen AC \& BÀrberi P (2008) Functional biodiversity: an agroecosystem approach. Agriculture, Ecosystems and Environment 127, 7-21.

Moonen AC, Castro Rodas N, Bàrberi P \& Petacchi R (2006) Field margin structure and vegetation composition effects on beneficial insect diversity at farm scale: a case study on an organic farm near Pisa. In: Landscape Management for Functional Biodiversity (eds WAH Rossing, L Eggenschwiler \& HM Poehling), IOBC wprs Bulletin 29, 77-80.

Natural England (2008a) Entry Level Stewardship Handbook, 2nd edn. Available at http://www.naturalengland.org.uk

Natural England (2008b) Environmental Stewardship. Higher Level Stewardship, Part A: Application Handbook, 2nd edn. Available at http://www.naturalengland.org.uk

NORRIS RF \& KOGAN M (2000) Interactions between weeds, arthropod pests, and their natural enemies in managed ecosystems. Weed Science 48, 94-158.

Norris RF \& Kogan M (2005) Ecology interactions between weeds and arthropods. Annual Review of Entomology 50, 479-503.

Paoletti MG \& Lorenzoni GG (1989) Agroecology patterns in Northern Italy. Agriculture, Ecosystems and Environment 27, 139-154.

PARK YL \& Tollefson JJ (2006) Development and economic evaluation of spatial sampling plans for corn rootworm Diabrotica spp. (Col., Chrysomelidae) adults. Journal of Applied Entomology 130, 337-342.

PARRIS K (2001) OECD Agri-biodiversity Indicators: Background Paper. OECD expert meeting on agri-biodiversity indicators, Zurich, Switzerland.

PERRY JN (1997) Statistical aspects of field experiments. In: Methods in Ecological and Agricultural Entomology (eds DR Dent \& MP Walton), 171-201. CABI Publishing, Wallingford, UK.

Perry JN, Liebhold AM, Rosenberg MS et al. (2002) Illustrations and guidelines for selecting statistical methods for quantifying spatial pattern in ecological data. Ecography 25, 578-600.

Ragaglini G, Moonen AC, Bàrberi P, Petacchi R, Rizzi I \& BonARI E (2005) Field-scale interactions between weeds and Aphis fabae Scop. (Homoptera: Aphididae) in conventional and low-input sugarbeet. In: Proceedings 13th EWRS Symposium, Bari, Italy, 19-23 June.

Risch SJ (1987) Agricultural ecology and insect outbreaks. In: Insect Outbreaks (eds BARbosa P \& Schultz JC), 217-238. Academic Press, New York, NY, USA. 
Risch SJ \& CARroll CR (1986) Effects of seed predation by a tropical ant on competition among weeds. Ecology 67, 1319-1327.

Schweitzer JA, Bailey JK, Bangert RK, Hart SC \& Whiтнам TG (2008) The role of plant genetic variation in determining above- and belowground microbial communities. In: Microbial Ecology of Aerial Plant Surfaces (eds MJ Bailey, AK Lilley, TM Timms-Wilson \& PTN SpencerPhillips), 107-120. CABI Publishing, Wallingford, UK.

Shearin AF, Reberg-Horton SC \& Gallandt ER (2008) Cover crop effects on the activity-density of the weed seed predator Harpalus rufipes (Coleoptera: Carabidae). Weed Science 56, 442-450.

Shuster SM, LONSDORF EV, Wimp GM, Bailey JK \& Whitham TG (2006) Community heritability measures the evolutionary consequences of indirect genetic effects on community structure. Evolution 60, 991-1003.

Siebert R, Toogood M \& Knierim A (2006) Factors affecting European farmers' participation in biodiversity policies. Sociologia Ruralis 46, 318-340.

de Snoo G, Burgio G, Eggenschwiler L et al. (2006) Success stories in landscape management for functional biodiversity: an assessment from 5 west-European countries. In: Landscape Management for Functional Biodiversity (eds WAH Rossing, L Eggenschwiler \& HM Poehling), IOBC wprs Bulletin 29, 29-32.

Soler R, Harvey JA, Kamp AFD et al. (2007) Root herbivores influence the behaviour of an aboveground parasitoid through changes in plant-volatile signals. Oikos 116, 367376.

Southwood TRE \& WAY MJ (1970) Ecological background to pest management. In: Concepts of Pest Management (eds RL Rabb \& FE Guthrie), 6-29. North Carolina State University, Raleigh, NC, USA.

Storkey J (2006) A functional group approach to the management of UK arable weeds to support biological diversity. Weed Research 46, 513-522.

Thies C, Steffan-Dewenter I \& Tscharntke T (2003) Effects of landscape context on herbivory and parasitism at different spatial scales. Oikos 101, 18-25.
Tindall KV \& Stout MJ (2001) Plant-mediated interactions between the rice water weevil and fall armyworm in rice. Entomologia Experimentalis et Applicata 101, 9-17.

Tooley J \& Brust G (2002) Weed seed predation by carabid beetles. In: The Agroecology of Carabid Beetles (ed. JM Holland), 215-228. The Game Conservancy Trust, Fordingbridge, UK.

Tscharntke T \& BRAndl R (2004) Plant-insect interactions in fragmented landscapes. Annual Review of Entomology 49, 405-430.

Westerman PR, Wes JS, KropfF MJ \& VAn der Werf W (2003) Annual losses of weed seeds due to predation in organic cereal fields. Journal of Applied Ecology 40, 824836.

Westerman PR, Liebman M, Menalled F, Heggenstaller AH, Hartzler RG \& Dixon PM (2005) Are many little hammers effective? Velvetleaf (Abutilon theophrasti) population dynamics in two and four year crop rotation systems. Weed Science 53, 382-392.

Whitham TG, Martinsen GD, Young W et al. (2003) Community and ecosystem genetics: a consequence of the extended phenotype. Ecology 84, 559-573.

Whitham TG, Bailey JK, Schweitzer JA et al. (2006) A framework for community and ecosystem genetics: from genes to ecosystems. Nature Reviews Genetics 7, 510-523.

Wilson PJ \& Aebisher NJ (1995) The distribution of dicotyledonous arable weeds in relation to distance from the field hedge. Journal of Applied Ecology 32, 295-310.

Wilson GA \& HART K (2002) Farmer participation in agrienvironmental schemes: towards conservation-oriented thinking? Sociologia Ruralis 41, 254-274.

World BAnK (2006) Latin America: Multi-Country CapacityBuilding for Compliance with the Cartagena Protocol on Biosafety (P095169). Environmental Assessment Report, December 2006.

ZANin G, Berti A \& Riello L (1998) Incorporation of spatial variability into the weed control decision-making process. Weed Research 38, 107-118. 